\title{
Dietary Patterns in Japanese Migrants to Southeastern Brazil and Their Descendants
}

\author{
Marly A. Cardoso ${ }^{1,2}$, Gerson S. Hamada ${ }^{3}$, José M. P. de Souza ${ }^{4}$, Shoichiro Tsugane ${ }^{5}$ \\ and Shinkan Tokudome ${ }^{2}$
}

This paper describes the dietary patterns of people of Japanese ancestry living in São Paulo, Brazil. Two cross-sectional surveys using a food frequency questionnaire (in 1989 and 1995) and self-administered three-day food record (only in 1995) were carried out in randomly chosen firstgeneration (Japan-born) and second-generation (Brazil-born) Japanese living in the city of São Paulo $(n=166)$, aged $40-69$ years at the time of the first survey (1989). Daily intake of rice, bread, milk, fruits and coffee, and infrequent consumption of pork, green tea, black tea, tsukemono (pickled vegetables), seaweed and mushrooms were reported. The mean ( \pm standard deviation) daily proportions of energy from fat among Japan-born participants were $27.2 \pm 6.7 \%$ for men and $26.2 \pm 6.7 \%$ for women. The respective figures for Brazil-born Japanese were $30.1 \pm 7.4 \%$ and $29.5 \pm 6.4 \%$. These values were quite close to recent estimates for the general Brazilian population in metropolitan areas (about 30\%), but seem to be higher than available data from Japan (25.3\%). Dietary changes in this migrant population are discussed with focus on nutrients currently implicated in the etiology of major chronic diseases. J Epidemiol, 1997; 7 : 198-204.

dietary survey, food intake, ethnic groups, migrants, lifestyle, Brazil, Japan

Comparisons of morbidity profiles among people of Japanese ancestry living in Hawaii and the mainland US with those observed among US Caucasians and Japanese in Japan have provided valuable clues on the role of environmental factors in the etiology of cancers and other diseases. As a whole, morbidity patterns in migrants tend to be intermediate between those observed in Japan and the US, as exemplified by the incidence of cerebrovascular and coronary heart disease ${ }^{1,2)}$ and some cancers ${ }^{3}$. Differences in dietary pattems constitute a major component in the environmental changes experienced by migrant populations, and have been associated with several diseases with contrasting prevalence rates in the US and Japan ${ }^{4,5}$.

Japanese migration to Brazil was extensive in the first half of this century, particularly between 1926 and 1935. About 250,000 Japanese moved to Brazil between 1908 and 1978, and this is now the world's largest Japanese population outside Japan. Moreover, it was estimated that $1,168,000$ Japanese descendants were living in Brazil by 1988. More than half of these reside in the southeastern state of São Paulo and one fourth in its capital, the city of São Paulo ${ }^{6}$. Despite the contrast in the geographical environment and lifestyle in Brazil, Japan and the US, only in the last few years morbidity patterns in the large population of Japanese migrants to São Paulo and their descendants have been systematically investigated. Significant differences have been found in mortalities from coronary heart disease and diabetes mellitus (higher in migrants) and cerebrovascular disease (higher in Japanese in Japan) ${ }^{7}$, as well as in incidence rates of some cancers, which are either increased (prostate and breast) or decreased (stomach and liver) in migrants. By contrast with previous studies of Japanese migrants to the US, no differences were observed in the incidence of and mortality from colorectal cancer ${ }^{8,9}$.

The distinct morbidity patterns observed among people of Japanese ancestry in Japan, Brazil and the US may be partially

Received January 10, 1997 ; accepted March 21,1997.

${ }^{1}$ Division of Nutrition Research, Institute of Health, São Paulo, Brazil.

${ }^{2}$ Department of Public Health, Nagoya City University Medical School, Nagoya, Japan.

${ }^{3}$ Division of Epidemiology and Biostatistics, A. C. Camargo Hospital Research Center, Antônio Prudente Foundation, São Paulo, Brazil.

${ }^{4}$ Department of Epidemiology, School of Public Health, University of São Paulo, São Paulo, Brazil.

${ }^{5}$ Epidemiology and Biostatistic Division, National Cancer Center Research Institute, Chiba, Japan.

Address for correspondence : Marly Augusto Cardoso Division of Nutrition Research Institute of Health Rua Santo Antônio 590 01314-000 São Paulo(SP) - Brazil. 
explained by differences in dietary patterns in the three countries. Cerebrovascular and coronary heart disease, as well as stomach and colorectal cancer, are well-known examples of conditions closely related to dietary factors. This paper describes dietary patterns in people of Japanese ancestry living in the city of São Paulo. Dietary changes in this migrant population are discussed with a focus on nutrients currently implicated in the etiology of major chronic diseases.

\section{SUBJECTS AND METHODS}

\section{Study Population}

Two cross-sectional surveys were performed, at a 6-year interval, in randomly selected subjects of Japanese ancestry living in the city of São Paulo. Eligible subjects were either Japan-born (first-generation or Issei) or Brazil-born people of Issei parents (second-generation or Nisei) aged between 40 and 69 years (in 1989), selected from the database of a special household-based census of the Japanese population in Brazil performed in 1988.

Sampling strategies, participation rates and partial results of the first survey, conducted between August and September 1989 , have been reported elsewhere ${ }^{10}$. Two hundred fifty one subjects (90 first-generation and 161 second-generation Japanese) were fully examined and interviewed, including 118 men and 133 women. Dietary patterns in this survey were investigated by applying a food frequency questionnaire (FFQ). A second survey was performed between August and September 1995 with the same basic protocol, except that dietary patterns were estimated by the same FFQ used in 1989 and also by three-day food records (3-DFR). Of the subjects studied in 1989, 188 (75\%) were interviewed again in 1995. Of the original study population, 17 subjects $(7 \%)$ had died, 13 (5\%) had moved to Japan, 29 (12\%) were not found and 4 (2\%) refused to participate. Results presented here refer to 166 participants (66\% of those eligible) who completed both FFQ and the 3-DFR (in 1995).

\section{Assessment of dietary patterns}

Participants were interviewed at home by trained public health nurses and asked about their age, personal (including migration) and medical histories, smoking and drinking habits. Weight and height were measured in both surveys in a standardized fashion ${ }^{10)}$. Body mass index (BMI) was calculated by dividing the weight (in $\mathrm{kg}$ ) by the height squared (in $\mathrm{m}$ ). Medical data obtained in 1989 have been reported elsewhere ${ }^{10}$.

The FFQ used in both surveys has been adapted and translated from the Japanese version used in a cross-sectional epidemiologic study ${ }^{11}$. Subjects were asked the usual consumption frequency of items listed ( 31 items) during the previous year. Four frequency categories (and weights given in calculating the weekly consumption) were as follows: almost every day
(6), three to four times per week (3.5), one to two times per week (1.5), and rarely (0). Subjects were also asked about their preference to some foods (for instance salty, fried or baked food), use of sauces and type of fat used in cooking procedures.

In the 1995 survey, all participants were also requested to report their food intakes over three consecutive days, including two weekdays and one weekend day. Those agreeing to complete the food records were advised to provide detailed descriptions of each food, including the brand name of ingredients whenever possible. Details of recipes used for cooked foods were collected to estimate nutritional composition from the raw ingredients. After completion, possible ambiguities were eliminated by reviewing all entries, and all diet records were coded by the same nutritionist to reduce inter-subject variations. Portion sizes were estimated by reference to household measures, and converted into SI units ( $\mathrm{g}$ or $\mathrm{ml}$ ) with the aid of software developed for research in clinical nutrition ${ }^{12}$. Nutrient intakes were computed from the records using the most recent edition of Standard Food Composition Tables of Brazil ${ }^{133}$ and $\mathrm{Japan}^{144}$. Ethanol contents in alcoholic beverages consumed were estimated as follow: $6 \%$ for beer, $38 \%$ for pinga (distilled liquor from sugar cane), $16 \%$ for sake (fermented rice wine), and $12 \%$ for wine.

\section{Data analysis}

Body weight and height were shown as means \pm standard deviations (SD). Differences in each pair of measurements in the 1989 and 1995 surveys were calculated as means and 95\% confidence intervals (95\% CI). Food frequency questionnaire data obtained from the 1995 survey are presented as median (and quartile ranges) of weekly frequencies of intake of selected food items. The levels of daily nutrient and food stuffs intakes according to gender and generation, obtained from three-day food records in 1995, are presented as either means ( $\pm \mathrm{SD}$ ) or medians (and interquartile ranges). All calculations were performed with the aid of the software package Epi Info version 6.0.

\section{RESULTS}

\section{Characteristics of the participants}

Overall, 166 subjects completed both FFQs and the 3-DFR. Of them, 52 (26 males and 26 females) were Japan-born and 114 (51 males and 63 females) were Brazil-born Japanese. The mean ages $\pm S D$ were $66.8 \pm 7.8$ and $57.7 \pm 7.8$ years for Issei and Nisei participants, respectively.

The average ( \pm SD) body weight (in $\mathrm{kg}$ ) and height (in $\mathrm{cm}$ ) in the 1995 survey were $63.2 \pm 11.8 \mathrm{~kg}$ and $161.8 \pm 7.9 \mathrm{~cm}$ for men, and $53.2 \pm 8.2 \mathrm{~kg}$ and $151.4 \pm 5.9 \mathrm{~cm}$ for women. No major differences were observed in body weight when paired measurements from 1989 and 1995 surveys were compared. The mean of paired differences (both genders combined) was 
$-0.5 \mathrm{~kg}(95 \% \mathrm{CI}:-1.2,-0.2 \mathrm{~kg}$ ). The means ( \pm SD) for BMI (in $\left.\mathrm{kg} / \mathrm{m}^{2}\right)$ were $24.0 \pm 3.3$ and $23.4 \pm 3.0$ for men and women, respectively. Similar distributions of BMI were observed in both surveys (data not shown). In 1995 survey, $8 \%$ of the males and $11 \%$ of the females may be classified as obese (BMI> 30).

The proportions of current smokers were $52 \%$ for men and $7 \%$ for women, and the respective figures for regular drinkers were $31 \%$ and $1 \%$.

\section{Dietary patterns}

Table 1 shows the median and quartile ranges of weekly frequencies of intake of selected food items reported in the FFQ. The most prominent features were daily intakes (median weekly frequency $=6$ ) of rice, fruits, coffee, bread, milk, and vegetables. Unusual consumption (median weekly frequency $=0$ ) was reported for pork, ham and sausages, mushrooms, black tea, and pickled vegetables. Seaweed, green tea, and miso soup were more frequently consumed by Japan-born participants.
The use of vitamin supplements was infrequent; only $9 \%$ of the participants reported to take regularly complex B (vitamins B1, B2, B6 and B12) tablets. Some relevant eating habits were as follows: $44 \%$ of the subjects used to eat the fat from meat, $41 \%$ preferred fried foods and only $24 \%$ reported some preference to salty dishes.

Average daily energy and macronutrient intakes computed from 3-DFR obtained in 1995 are shown in Table 2 . The daily energy intake and the proportions of energy derived from proteins and carbohydrates varied little across gender and generation. However, more energy was acquired from fat in Brazilborn than Japan-born Japanese diets. Table 3 shows the median and quartile ranges of intake of selected micronutrients reported in the 3-DFR. The median daily intake of most nutrients corresponded to the recommended dietary allowances for the Japanese population, except for vitamin A, whose means in all groups (ranging from 639 to 870 UI) fell below the current recommendation of $1800-2000 \mathrm{UI}^{15)}$, and only $3.6 \%$ of the total subjects reported daily intakes higher than 1800 UI. On the

Table 1. Median weekly food frequencies (interquartile ranges) of selected food items estimated from food frequency questionnaire by gender and generation among people of Japanese ancestry living in the city of São Paulo, Brazil.

\begin{tabular}{lrrrrr}
\hline & \multicolumn{2}{c}{ Males } & \multicolumn{2}{c}{ Females } \\
\cline { 2 - 6 } Food items & Japan-born & Brazil-born & Japan-born & Brazil-born \\
\hline Bread & $6.0(1.5,6.0)$ & $6.0(3.5,6.0)$ & $6.0(1.5,6.0)$ & $6.0(1.5,6.0)$ \\
Pasta, noodles & $1.5(0,1.5)$ & $1.5(0,1.5)$ & $1.5(1.5,1.5)$ & $1.5(0,1.5)$ \\
Rice & $6.0(6.0,6.0)$ & $6.0(6.0,6.0)$ & $6.0(6.0,6.0)$ & $6.0(6.0,6.0)$ \\
Potatoes & $1.5(1.5,3.5)$ & $1.5(1.5,3.0)$ & $1.5(1.5,3.5)$ & $1.5(0,1.5)$ \\
Boiled beans & $1.5(0,6.0)$ & $3.5(1.5,6.0)$ & $1.5(1.5,6.0)$ & $1.5(0,3.5)$ \\
Soybean & $1.5(0,1.5)$ & $1.5(0,1.5)$ & $1.5(0,1.5)$ & $0(0,1.5)$ \\
Fruits & $6.0(3.5,6.0)$ & $6.0(3.5,6.0)$ & $6.0(3.5,6.0)$ & $6.0(6.0,6.0)$ \\
Carrots, pumpkins & $3.5(1.5,6)$ & $1.5(1.5,3.5)$ & $3.5(1.5,6.0)$ & $3.5(1.5,6.0)$ \\
Green vegetables & $3.5(1.5,6.0)$ & $3.5(1.5,6.0)$ & $3.5(1.5,6.0)$ & $3.5(1.5,6.0)$ \\
Other vegetables & $6.0(3.5,6.0)$ & $6.0(3.5,6.0)$ & $6.0(3.5,6.0)$ & $6.0(3.5,6.0)$ \\
Fish & $1.5(0,1.5)$ & $1.5(0,1.5)$ & $1.5(0,1.5)$ & $1.5(0,1.5)$ \\
Chicken & $1.5(1.5,3.5)$ & $1.5(1.5,1.5)$ & $1.5(0,3.5)$ & $1.5(1.5,3.5)$ \\
Beef & $3.5(1.5,6.0)$ & $3.5(1.5,6.0)$ & $3.5(1.5,3.5)$ & $1.5(1.5,3.0)$ \\
Pork & $0(0,0)$ & $0(0,0)$ & $0(0,0)$ & $0(0,0)$ \\
Ham, sausage & $0(0,1.5)$ & $0(0,0)$ & $0(0,1.5)$ & $0(0,1.5)$ \\
Eggs & $1.5(1.5,3.5)$ & $1.5(0,1.5)$ & $1.5(0,3.5)$ & $1.5(0,1.5)$ \\
Milk & $6.0(0,6.0)$ & $6.0(0,6.0)$ & $6.0(1.5,6.0)$ & $6.0(1.5,6.0)$ \\
Cheese & $1.5(0,1.5)$ & $1.5(0,3.5)$ & $0(0,3.5)$ & $1.5(0,6.0)$ \\
Mushrooms & $0(0,0)$ & $0(0,0)$ & $0(0,0)$ & $0(0,0)$ \\
Pickles & $0(0,1.5)$ & $0(0,0)$ & $0(0,1.5)$ & $0(0,1.5)$ \\
Green tea & $0.7(0,6.0)$ & $0(0,1.5)$ & $3.7(0,6.0)$ & $0(0,1.5)$ \\
Coffee & $6.0(3.5,6.0)$ & $6.0(6.0,6.0)$ & $6.0(1.5,6.0)$ & $6.0(3.5,6.0)$ \\
Tea & $0(0,3.5)$ & $0(0,1.5)$ & $0(0,3.5)$ & $0(0,3.5)$ \\
Seaweeds & $1.5(0,6.0)$ & $0(0,1.5)$ & $1.5(0,3.5)$ & $0(0,1.5)$ \\
Miso soup & $3.5(0,6.0)$ & $1.5(0,1.5)$ & $2.5(1.5,6.0)$ & $1.5(0,1.5)$ \\
\hline & & & &
\end{tabular}


other hand, the average daily intake of vitamin $\mathrm{C}$ ranged from 175 to $211 \mathrm{mg}$ in all groups and only $9 \%$ of the participants reported daily intakes lower than $50 \mathrm{mg} /$ day.

Table 4 compares the median intake (and quartile ranges) of selected foods and food groups, as computed from 3DFR, in all subjects according to gender and generation. The most noticeable differences may be summarized as follow: fish and miso soup were more commonly consumed by Japan-born migrants. Brazil-born participants had a considerably higher intakes of oils and fats, legumes (mainly kidney beans), chicken and red meats (e.g., beef, pork and sausages), dairy products (e.g., cheese and yoghurt) and coffee. Seaweed and mushrooms intakes were reported by a few Japan-born participants ( $n=22$ ). The servings from bread and cereals, fruits, vegetables and milk were similar in all groups. Infrequent consumption of soybean products, pick- led vegetables (mainly tsukemono) and green tea were observed in both generations of Japanese migrants. The alcohol intake (derived mainly from beer and sake) among females was unusual, and the average values $( \pm S D)$ tended to be higher in younger than older males $(8.1 \pm 16.9 \mathrm{~g} / \mathrm{day}$ for 47-59 years and $0.1 \pm 0.5 \mathrm{~g} /$ day for older males).

\section{DISCUSSION}

To our knowledge dietary patterns among people of Japanese ancestry living in Brazil have not been previously compared. Nevertheless, some potential limitations of this first attempt should be kept in mind. Firstly, since the numbers of subjects are small and the Japan-born migrants are on average 9 years older than Brazil-born participants, the comparisons between first- and second-generation should be regarded here

Table 2. Mean daily intake ( \pm standard deviation ) and percent contribution to total energy of macronutrients estimated from three-day food records by gender and generation in people of Japanese ancestry living in São Paulo, Brazil.

\begin{tabular}{|c|c|c|c|c|}
\hline \multirow[b]{2}{*}{ Nutrient } & \multicolumn{2}{|c|}{ Males } & \multicolumn{2}{|c|}{ Females } \\
\hline & Japan-born & Brazil-born & Japan-born & Brazil-born \\
\hline Energy (kcal) & $1958.3 \pm 442.9$ & $2159.2 \pm 611.5$ & $1707.3 \pm 547.9$ & $1779.3 \pm 492.6$ \\
\hline Protein $(\mathrm{g})$ & $78.1 \pm 23.9$ & $82.5 \pm 28.5$ & $64.2 \pm 22.9$ & $67.5 \pm 20.6$ \\
\hline Carbohydrate (g) & $292.8 \pm 74.5$ & $298.8 \pm 101.4$ & $258.3 \pm 96.9$ & $252.1 \pm 74.8$ \\
\hline Total fat $(g)$ & $58.9 \pm 20.1$ & $71.6 \pm 24.7$ & $49.8 \pm 20.6$ & $58.8 \pm 21.2$ \\
\hline$\%$ protein energy & $15.9 \pm \quad 2.9$ & $15.2 \pm \quad 2.4$ & $14.9 \pm \quad 2.8$ & $15.2 \pm 2.4$ \\
\hline \%carbohydrate energy & $59.6 \pm 8.1$ & $55.5 \pm 9.7$ & $60.4 \pm 9.1$ & $57.0 \pm 8.9$ \\
\hline \% total fat energy & $27.2 \pm \quad 6.7$ & $30.1 \pm 7.4$ & $26.2 \pm \quad 6.7$ & $29.5 \pm 6.4$ \\
\hline
\end{tabular}

Table 3. Median daily intake (interquartile ranges) of selected micronutrients estimated from three-day food records by gender and generation in people of Japanese ancestry living in São Paulo, Brazil.

\begin{tabular}{lcccc}
\hline & \multicolumn{2}{c}{ Males } & \multicolumn{2}{c}{ Females } \\
\cline { 2 - 5 } Nutrient & Japan-born & Brazil-born & Japan-born & Brazil-born \\
\hline Calcium (mg) & 788.6 & 624.0 & 644.4 & 696.8 \\
& $(595.9,985.8)$ & $(440.4,969.9)$ & $(496.1,878.6)$ & $(521.5,912.3)$ \\
Vitamin A (IU) & 555.5 & 545.6 & 507.3 & 523.5 \\
& $(446.6,856.3)$ & $(375.1,868.0)$ & $(369.6,876.6)$ & $(405.6,911.7)$ \\
Thiamin (mg) & 0.97 & 0.96 & 0.89 & 0.86 \\
& $(0.73,1.20)$ & $(0.70,1.41)$ & $(0.63,1.14)$ & $(0.65,1.1)$ \\
Riboflavin (mg) & 1.61 & 1.58 & 1.11 & 1.55 \\
& $(1.15,2.18)$ & $(0.90,2.19)$ & $(0.91,1.80)$ & $(1.17,2.37)$ \\
Niacin (mg) & 14.3 & 16.5 & 14.3 & 12.9 \\
& $(12.0,20.2)$ & $(12.6,20.9)$ & $(8.9,16.9)$ & $(10.9,16.5)$ \\
Vitamin C (mg) & 173.0 & 153.0 & 162.8 & 181.5 \\
& $(113.0,281.5)$ & $(79.7,279.8)$ & $(84.1,274.6)$ & $(127.9,257.3)$ \\
& & & & \\
\hline
\end{tabular}


Table 4. Medain daily intake (interquartile ranges) of selected food stuffs and alcohol ( $g /$ day) estimated from three-day food records by gender and generation among people of Japanese ancestry living in the city of São Paulo, Brazil.

\begin{tabular}{|c|c|c|c|c|}
\hline \multirow[b]{2}{*}{ Food stuffs } & \multicolumn{2}{|c|}{ Males } & \multicolumn{2}{|c|}{ Fermales } \\
\hline & Japan-born & Brazil-born & Japan-born & Brazil-born \\
\hline Bread + cereals & $206(177,245)$ & $213(167,267)$ & $177(133,233)$ & $179(127,221)$ \\
\hline Potatoes & $14(0,33)$ & $25(0,47)$ & $22(0,45)$ & $13(0,33)$ \\
\hline Sugar, confectionaries & $84(11,157)$ & $80(33,225)$ & $37(12,100)$ & $73(30,134)$ \\
\hline Oils and fats & $13(11,14)$ & $17(12,22)$ & $12(10,15)$ & $13(10,17)$ \\
\hline Legume & $7(0,24)$ & $18(10,29)$ & $5(0,17)$ & $12(6,20)$ \\
\hline Soybean products & $0(0,17)$ & $0(0,0)$ & $0(0,10)$ & $0(0,0)$ \\
\hline Fruits & $257(167,333)$ & $243(53,490)$ & $232(157,460)$ & $340(173,470)$ \\
\hline Vegetables & $142(104,252)$ & $157(102,224)$ & $128(70,183)$ & $155(100,200)$ \\
\hline Fish and shellfishes & $33(3,59)$ & $17(0,50)$ & $37(7,53)$ & $1(0,42)$ \\
\hline Chicken & $0(0,40)$ & $13(0,67)$ & $0(0,40)$ & $27(0,53)$ \\
\hline Red meat & $57(33,100)$ & $99(53,148)$ & $55(17,88)$ & $60(12,102)$ \\
\hline Egg & $17(0,25)$ & $5(0,27)$ & $3(0,20)$ & $1.3(0,20)$ \\
\hline Milk & $120(0,170)$ & $100(0,190)$ & $110(40,160)$ & $133(43,238)$ \\
\hline Dairy products & $0(0,7)$ & $5(0,13)$ & $0(0,15)$ & $5(0,14)$ \\
\hline Pickles & $0(0,17)$ & $0(0,0)$ & $0(0,27)$ & $0(0,0)$ \\
\hline Soy sauce & $7(3,12)$ & $3(0,10)$ & $7(3,10)$ & $7(0,10)$ \\
\hline Green tea & $0(0,167)$ & $0(0,0)$ & $0(0,100)$ & $0(0,0)$ \\
\hline Coffee & $67(33,243)$ & $162(75,225)$ & $67(40,202)$ & $167(67,233)$ \\
\hline Miso soup & $160(0,240)$ & $0(0,80)$ & $138(0,240)$ & $0(0,160)$ \\
\hline Alcohol & $0(0,3)$ & $0(0,7)$ & $0(0, \quad 0)$ & $0(0,0)$ \\
\hline
\end{tabular}

as tentative, rather than definitive. Secondly, despite the fact that food frequency questionnaires were found to be adequately reproducible in Japanese populations ${ }^{16}$, this issue has not been formally addressed in our study population. However, food frequency questionnaires are likely to be reliable to determine extreme categories of habitual food intake (that is, which foods and food groups are either rarely or very commonly consumed $)^{17}$. A third limitation refers to three-day food records, which usually provide adequate information on the levels of macronutrient intake, but tend to be less accurate in relation to micronutrients due to intra-individual day-to-day variations ${ }^{18)}$.

The highest intakes of oils and fats, red meat, chicken and dairy products observed in Brazil-born Japanese may be used to explain the differences in total fat intake. The proportion of total energy intake derived from fat has been found to increase in Japanese migrants to the US when compared to Japanese living in Japan ${ }^{5}$. Analogous results are reported here. The figures for Japanese migrants living in São Paulo are quite close to recent estimates for the general Brazilian population in metropolitan areas (about $30 \%)^{19}$, but still lower than those in US Caucasians aged $35-64$ years $(38-39 \%)^{20)}$. However, the average concentrations $( \pm S D)$ of serum cholesterol $(208 \pm 45$ $\mathrm{mg} / \mathrm{dl}$ ) and triglycerides (185 $\pm 142 \mathrm{mg} / \mathrm{dl}$ ) measured in Japanese migrants to São Paulo in the 1989 survey $^{10)}$ were slightly higher than those found in comparable cross-sectional surveys in Japan ${ }^{21)}$, despite the fact that Brazil and Japan have recently experienced, almost in parallel, significant changes in dietary patterns and fat consumption. For instance, between 1946 and 1990 the average proportion of energy intake derived from fat in Japan, as estimated by nation-wide householdbased nutrition survey, has increased from $7.0 \%$ to $25.3 \%{ }^{22}$. Analogous trends were recently observed in both countries in relation to red meat consumption ${ }^{19,23)}$.

In the present study, changes in the traditional Japanese diet could be observed with the unusual consumption of typical Japanese food stuffs in the participants from São Paulo surveys. Some foods and food groups more commonly consumed by Japanese living in Japan than in São Paulo, such as soybean products, fish and green tea ${ }^{2234}$, have been suggested to protect against coronary heart disease ${ }^{2425)}$, while fresh fruit (largely consumed by Japanese living in São Paulo) may prevent stroke ${ }^{4}$. Further, gastric cancer is positively associated with high salt intake and negatively associated with high intake of fresh vegetables and fruits ${ }^{26)}$. Therefore, dietary factors may interact with many other causal determinants to account for the major differences in the mortality from coronary heart disease, stroke and gastric cancer in people with Japanese ancestry in Brazil and Japan 7 . Such an interaction seems to be particularly complex in the pathogenesis of hemorrhagic stroke, which remains more prevalent in Japan than in any other industrialized country. 
Colon cancer is a classical example of disease related to environmental (particularly dietary) risk factors. Its incidence among Japanese migrants to Hawaii tends to reach the high figures usually observed in US Caucasians within one or two generations ${ }^{2 n}$. Nevertheless, similar incidence rates were reported among Japanese living in Brazil and Japan ${ }^{8)}$. The incidence of colon cancer in the general population of São Paulo (about 14 per 100,000), albeit significantly higher than in Japan ${ }^{8}$, was still considerably lower than those in the US and western Europe $(25-35 \text { per } 100,000)^{27}$. However, recent dietary and lifestyle changes in Japan and Brazil are likely to modify substantially this epidemiological scenario.

In conclusion, differences in dietary patterns among people sharing the same genetic background, as those observed here, may provide a rational basis for further investigations of risk factors for several chronic diseases. Several in-depth studies of environmental risk factors in cancers are now being planned or performed in parallel, with comparable methods, among Japanese living in São Paulo and Japan, and efforts have been made to improve and validate the current version of the food frequency questionnaire to be applied in studies of migrant Japanese populations in Brazil.

\section{Acknowledgements}

The authors express their thanks to the field team involved in both surveys, and particularly Lucy Ito, who coordinated the dietary survey, Cecília Sakaue and Vanessa Trogiani, who provided invaluable technical support. Thanks are extended to Satoshi Sasaki for critical advice, and to Michael Fahey for reviewing the manuscript. This study was supported by a grantin-aid from the International Science Research Program of the Ministry of Education, Science, Sports and Culture of Japan ( Monbusho). MAC was supported by a research fellow scholarship from the Brazilian agency CAPES (BEX 1593/95-1).

\section{REFERENCES}

1. Syme SI, Marmot MG, Kagan A, Rhoads G. Epidemiological studies of coronary heart disease and stroke in Japanese men living in Japan, Hawaii and California. Am J Epidemiol 1975; 102: 477-480.

2. Benfante R, Yano K, Hwang L-J, et al. Elevated serum cholesterol is a risk factor for both coronary heart disease and thromboembolic stroke in Hawaiian Japanese men. Implications of shared risk. Stroke 1994; 25: 814-820.

3. Dunn JE. Cancer epidemiology in populations of the United States - with emphasis on Hawaii and California and Japan. Cancer Res 1975; 35: 3240-3245.

4. Gillman MW, Cupples LA, Gagnon D, et al. Protective effect of fruits and vegetables on development of stroke in men. JAMA 1995; 273: 1113-1117.

5. Kagan A, Harris BR, Winkelstein W, et al.
Epidemiologic studies of coronary heart disease and stroke in Japanese men living in Japan, Hawaii and California: demographic, physical, dietary and biochemical characteristics. J Chron Dis 1974; 27: 345-364.

6. Center for Japan-Brazil Studies. The Result of Survey for Japanese Population in Brazil. São Paulo, Center for Japan-Brazil Studies, 1988.

7. Tsugane S, Gotlieb SLD, Laurenti R, Souza JMP, Watanabe S. Mortality and cause of death among firstgeneration Japanese in São Paulo, Brazil. Int J Epidemiol 1989; 18: 647-651.

8. Tsugane S, Gotlieb SLD, Laurenti R, Souza JMP, Watanabe $S$. Cancer mortality among Japanese residents of the city of São Paulo, Brazil. Int J Cancer, 1990; 45: 436-439.

9. Tsugane S, Souza JMP, Costa ML, et al. Cancer incidence rates among Japanese immigrants in the city of São Paulo, Brazil, 1969-78. Cancer Causes \& Control 1990; 1: 189-193.

10. Tsugane S, Hamada GS, Souza JMP, et al. Lifestyle and health related factors among randomly selected Japanese residents in the city of São Paulo, Brazil and their comparisons with Japanese in Japan. J Epidemiol 1994; 4: 37-46.

11. Tsugane $S$, Gey F, Ichinowatari $Y$, et al. Cross-sectional epidemiologic study for assessing cancer risks at the population level. I. Study design and participation rate. J Epidemiol 1992; 2: 75-81.

12. Anção NS, Tudisco ES, Sigulem D. Sistema de apoio à decisão em nutrição versão 2.5. São Paulo, Centro de Informática em Saúde, Escola Paulista de Medicina, Universidade Federal de São Paulo, 1995.

13. Fundação Instituto Brasileiro de Geografia e Estatísticã FIBGE. Table of Food Composition. 3rd ed. Rio de Janeiro, FIBGE, 1985 (in Portuguese).

14. Resources Council, Science and Technology Agency. Standard Tables of Food Composition in Japan. 4th ed. Tokyo, Women's University of Nutrition Press, 1993.

15. Ministry of Health and Welfare, Japan. Recommended Dietary Allowances for the Japanese. 5th revision. Tokyo, Daiichi Shuppan, 1996.

16. Tsubono Y, Nishino Y, Fukao A, Hisamichi S, Tsugane $S$. Temporal change in the reproducibility of a selfadministered food frequency questionnaire. Am J Epidemiol 1995; 142: 1231-1235.

17. Friedenreich CM, Slimani N, Riboli E. Measurement of past diet: review of previous and proposed methods. Epidemiol Rev 1992; 14: 177-196.

18. Willett W. Nutritional Epidemiology. Oxford, Oxford University Press, 1990.

19. Monteiro CA, Mondini L, Souza ALM, Popkin BM. The nutrition transition in Brazil. Eur J Clin Nutr 1995; 49 : 105-113. 
20. Block G, Subar AF. Estimates of nutrient intake from a food frequency questionnaire: the 1997 National Health Interview Survey. J Am Diet Assoc 1992; 92: 969-977.

21. Tsugane S, Gey F, Ichinowatari Y, et al. Cross-sectional epidemiologic study for assessing cancer risks at the population level. II. Baseline data and correlation analysis. J Epidemiol 1992; 2: 83-89.

22. Ministry of Health and Welfare. Report of the National Nutrition Survey in 1993. Tokyo, Daiichi-Shuppan, 1995 (in Japanese).

23. Okayama A, Ueshima H, Marmot MG, et al. Different trends in serum cholesterol levels among rural and urban populations aged 40-59 in Japan from 1960 to 1990. J Clin Epidemiol 1995; 48: 329-337.

24. Anderson JW, Johnstone BM, Cook-Newell ME. Metaanalysis of the effects of soy protein intake on serum lipids. N Engl J Med 1995; 333: 276-282.

25. Imai K, Nakachi K. Cross sectional study of effects of drinking green tea on cardiovascular and liver diseases. BMJ 1995; 310: 693-696.

26. Kono $S$, Hirohata $T$. Nutrition and stomach cancer. Cancer Causes \& Control 1996; 7: 41-55.

27. Potter JD. Nutrition and colorectal cancer. Cancer Causes \& Control 1996; 7: 127-146. 